\title{
SNAFUS: An Evolutionary Perspective ${ }^{1}$
}

\author{
Kim Sterelny \\ Philosophy Program \\ Australian National University and \\ Victoria University of Wellington \\ kimbo@coombs.anu.edu.au \\ Kim.Sterelny@vuw.ac.nz
}

\section{Dual Inheritance and Human Evolution}

Ordinary human action involves solving problems with a high information load. Richerson and Boyd (2005) have made this point vivid through a series of examples which show that traditional cultures depend on information-intensive life ways: forager decision making, for example, depends on a rich mix of social, ecological, and technical competence. This is especially clear of those peoples (like the Inuit and aboriginals of inland Australia) who live in extreme environments. But it is true more generally: as I have argued elsewhere, the distinctive ecological adaptation of humans is collective, technologically and informationally-mediated extraction of resources from their environment (Sterelny 2006 and forthcoming).

In many cases, the information on which human life ways depend has been accumulated incrementally, by a selectionlike process. Inuit life ways, for example, depend on an array of impressive technological innovations in building shelters; in such hunting weapons as harpoons; in new uses of materials including sown clothing, kayaks, and the like. A few of these might have been invented whole, by inspiration or lucky accident. But most innovations come through cycles of gradual improvement (Shennan 2002). Thus small-scale human life ways depend on information accumulated gradually, and transmitted reliably to the next generation. Natural history databases and traditional technologies are accumulated by trial, improvement, and transmission. They depend on some version of adaptive cultural evolution.

However, human cognitive response to our environment is strikingly variable, and my focus in this article is on constraints on cultural evolution. Thus, for example, many cultures are prisoners of vastly disabling beliefs about the polluting power of female menstruation. So while in some aspects, the people of particular cultures respond to their world in an extraordinarily nuanced, subtle, and informed way, in others these very same people will seem barking mad. The Inuit superbly exemplify the power of the processes of cultural adaptation to build effective responses to a harsh world. But as Robert Edgerton points out, the Inuit had many (apparently) irrational and costly beliefs about their environment as well. In particular, they populated it with nonexistent dangers: giant fish and birds, ghosts and spirits. These misconceptions of their environment were not free: the Inuit altered their foraging patterns to avoid these supposed dangers, and invested in expensive ritual protections (Edgerton 1992: 60-61).

So while the mechanisms of cultural evolution can build informationally mediated adaptations to challenging environments, there are also significant limits on adaptation mediated by cultural inheritance. Identifying the nature and extent of constraints on selection is a familiar project in evolutionary biology and especially evolutionary developmental biology, beginning with debates on adaptationism (Dupré 1987; Orzack and Sober 2001). However, this project was originally framed by the assumption that all inheritance was genetic inheritance. In this article, I reframe it using a dual inheritance model. In human evolution, some cross-generational similarities depend on culturally mediated learning by offspring from their parents and their parents' cohort (see, e.g., Tomasello 1999; Sterelny 2003; Jablonka and Lamb 2005; Richerson and Boyd 2005). As we shall see, this difference in inheritance mechanism leads to differences in the power of selection to shape phenotypes.

Adaptation depends on selective environments. For example, adaptive landscapes must be smooth and relatively stable if cumulative evolution is to build adaptive complexes. So the capacity of a lineage to respond to selection is blocked if genetic distance fails to correspond with phenotypic difference, but it is also blocked if phenotypic difference fails to correspond to fitness differences. The idea is this. Consider three 
possible phenotypes, $\mathrm{A}, \mathrm{B}$, and $\mathrm{C}$, where $\mathrm{B}$ is phenotypically between $\mathrm{A}$ and $\mathrm{C}$. Selection cannot straightforwardly take the population from $\mathrm{A}$ to $\mathrm{C}$ unless $\mathrm{B}$ is also intermediate in fitness between $\mathrm{A}$ and $\mathrm{C}$. Selective environments and their role in the limits of adaptive response are the focus of Sections 2-4. I shall argue that the environment plays a different role in dual inheritance models of evolution than in genic models. But selection also depends on variation. So one approach to understanding constraints on selection is through a theory of the generation and retention of variation. If there are limits or biases in the generation of variation, those will influence evolutionary trajectories (Wallace Arthur [2004] christened this effect "developmental drive"). Moreover, if variation cannot be retained in a population, this too will limit the power of selection to sculpt adaptive changes.

To what extent is genetic variation a model for cultural variation? In previous work I have argued that though the flow of genes across the generations is not the only evolutionarily important inheritance system, it is of unique biological importance (Sterelny 2001, 2004), and not just because it is ancient and universal (other mechanisms tend to be restricted to specific clades). It has characteristics that make possible the evolution of complex adaptations by enabling a flow of selectable variation. Genetic inheritance is high-fidelity. The supply of potential genetic variation is very large indeed, and this large space of genetic possibility corresponds to a large space of phenotypic possibility. As Maynard Smith (2000) emphasized, the relationship between gene and trait is arbitrary. ${ }^{2}$ Moreover, sometimes, small genetic changes have reoccurring phenotypic effects.

So in most lineages, the genotype-phenotype map supports continued evolutionary plasticity. Lewontin (1978) famously pointed out that response to selection depends on phenotypes being "quasi-independent." It must be possible for some aspects of the phenotype to change without every aspect changing: mutations that improve camouflage will not be selected if they have effects on many other aspects of a moth's phenotype (for some are bound to be deleterious). While the extent to which phenotypic traits are independent of each other is unknown, and no doubt varies both from trait to trait and lineage to lineage, we know from the continuing history of evolutionary change that many gene-based developmental systems satisfy this criterion in important ways.

So gene-based phenotypes are highly evolvable. Can the same be said for those aspects of phenotype that are systematically influenced by cultural transmission? Language and other representational media certainly generate a large space of potential cultural variants. The issue of fidelity is important and contested: Dawkins has consistently argued that complex adaptation depends on cumulative evolution, and cumulative evolution depends on a specific form of high fidelity replication. If a replicator is copied from generation $\mathrm{N}$ to $\mathrm{N}+1$ with an error, that error must itself be copied to generation $\mathrm{N}+2$, should the organism survive to reproduce (Dawkins 1982a; Dawkins 2004). For small improvements can be preserved only if inheritance meets this "replicator condition." While gene-based inheritance meets this condition, there is no consensus that cultural transmission does. In my (2001), I focused on this issue, and so have Sperber (1996), Atran (2001), and Gil-White (2005). As I now see it, this generalized skepticism is a mistake, under-estimating the ways through which children's learning environments are scaffolded (Sterelny 2003). Rather, the fidelity issue is: under what circumstances is cultural transmission of sufficient fidelity to support the cumulative evolution of adaptive complexes, and what information can be transmitted with such fidelity?

The focus on fidelity is itself unfortunate. As we shall see (in Section 4), fidelity is not the only constraint on the retention of variation. Moreover, the relationship between inherited developmental resources and agent phenotype is also important. Even if transmission is of high fidelity, a rich supply of variation in the population of replicators may not correspond to a rich and selectable array of phenotype variation. Three issues arise: (1) To what extent is information from the parental generation transmitted as a seamless whole; to what extent is transmission modular, so different elements in the package vary independently from one another? (2) Genes do not have to determine phenotypes to be selectable in virtue of their phenotypic effects. But they do have to be difference makers. If selection is to discriminate between them, different alleles of the same gene must induce consistent differences in a trait. The same is true of culturally transmitted information. For dual inheritance and selection to build complex adaptation, the natural history databases, artisan skills, or hunting techniques a child acquires from a parent need not determine those aspects of a child's phenotype. But differences in these information packages must result in differences in phenotypes. Fidelity is not enough: differences that are preserved and transmitted must be consistently expressed. Moreover, those differences must develop relatively robustly; the development of those different phenotypes cannot be too sensitive to other variations in the environment or in developmental resources. Culture might be of pervasive developmental importancecausally consequential to most of our life-without being a difference maker, without controlling variation in human phenotype. (3) Let us suppose that culturally transmitted information packages are difference makers. What is the width of variation in culturally transmitted information on phenotypes? Does it generate selectable differences in many aspects of human phenotypes, or only in a few? We focus on these issues in Section 5 .

I shall begin with issues that derive from the nature of selective environments, and then move on to variation and its expression. 


\section{Maladaptation, Levels of Selection, and Fitness Traps}

One important cause of maladaptation is conflict of interest. Individually adaptive choice often sums to collective maladaptation. Freeloading can both prevent mutually beneficial cooperation from establishing, and erode if it does establish. Easter Island is a famous example of a maladaptive outcome: an island paradise reduced to an eroded barren, littered with broken statues and waring clans. In his Collapse, Jared Diamond wonders about the psychology of maladaptive choice:

I have often asked myself, 'What did the Easter Islander who cut down the last palm tree say while he was doing it?' Like modern loggers, did he shout "Jobs, not trees'? Or 'Technology will solve our problems, never fear, we'll find a substitute for wood'. Diamond 2005: 114)

Much more likely, he shouted: "at least those bastards in the $\mathrm{XYZ}$ clan will not get this one." Unless agents are likely to share in the benefit of a collectively optimal decision, they are unlikely to make collectively optimizing decisions. ${ }^{3}$ In human social worlds, conflict between levels of selection is likely to be an important source of maladaptation. For there is reason to expect selection on individuals and on groups to be both strong and conflicting (Sober and Wilson 1998). It is conflicting because human societies are not egalitarian: inequalities (and perhaps even differentiation) lead to conflicts of interest. Resources are available, and it is up for grabs who gets most. For example, a shift to agricultural life and the opportunities to accumulate a surplus that agriculture makes possible certainly favored an elite that had access to that surplus. It is not at all clear that it favored others in emerging agricultural communities (Sahlins 1968; Diamond 1992, 1998).

Of course, the extent of inequality is itself highly variable. It is routinely argued that small-scale foraging social worlds are egalitarian. Boehm (1999) is one of those who argue that forager social worlds are egalitarian, but he notes that they are egalitarian in a limited sense: adult males do not differ markedly in wealth and power. Gender inequality generates conflicts of interest, and as Edgerton has noted, in many social worlds, including small-scale social worlds, the relationship between the sexes is deeply poisoned, because the consequences of inequality are noted and resented. Within Tasmanian aboriginal society (an indisputably small-scale forager society), inter-gender relations were so bad that Tasmanian aboriginal women chose to associate with sealers and whalers (in the early 19th century, these were not famous for their gentle ways with women) rather than the men of their own culture. Gender politics contributed to the extinction of the indigenous culture (Windshuttle 2002).

Edgerton's own poster example of a gender diaster is the Gusii. He charmingly describes the Gusii wedding night thus:
... the bride refused to disrobe or go to bed, and she did everything in her ... power to prevent her husband achieving penetration. This behaviour was traditional; girls were taught to resist ... including a practice ... in which the vaginal muscles were kept so tense that penetration was ... impossible. It was also said that a fierce bride might prevent her husband from successfully achieving intercourse for as long as a week, but more commonly, young male friends of the groom ... intervened and helped the groom by holding the bride's legs apart ... once intercourse finally took place, the husband was obliged to repeat it as often as possible ... six times was the minimally respectable number ... and in the process to cause his bride as much pain as possible (pp 84-85)

The women did not hold back either: Edgerton describes a custom of adolescent girls involving the prolonged sexual teasing of their just circumcised male peers, the aim being to induce an erection that would burst their unhealed incisions (see also Mayer 1952; LeVine 1959). No direct evidence is given that the Gusii, individually or collectively, paid a fitness cost for inter-gender hostility, but with partnerships like these, they surely needed no enemies. In saying this, there is an important question over which I have glided. Unequal sexual divisions of labor and resources clearly serve the economic interests of males, and we can usually assume economic benefit translates into fitness benefit. But men need healthy and co-operative mothers for their potential children, so it is not so obvious that men profit biologically from taking the lion's share of whatever is available, for it might reduce the capacity of their potential partners to bear and rear children. Moreover, resentment imposes fitness costs on males. However, in an unequal social world, individual males may well not be able to defect from prevailing practices with profit. In doing so, it is likely that their standing with other males will decline (as they lose control of resources and male allies) without ceasing to be a target of female suspicion and resentment.

In other words, the Gusii males may have found themselves in a fitness trap: a situation created by a strategy that sweeps the population because it is individually advantageous when not universal, but once fixed, the strategy reduces the absolute fitness of everyone. There is reason to suspect that many traits maintained by cultural transmission are maladaptive fitness traps. The phenomenon itself is not peculiar to traits whose development depends on culture. Gould and Lewontin identify it in their celebrated paper critiquing adaptationism. They point out that a trait can invade by giving its bearers a relative advantage (initially, perhaps even an absolute advantage), but as the trait is driven to fixation, it reduces the overall fitness of the population. Their example is of a mutation that doubles the fecundity of individual females. It would sweep the population, but would as it fixates lower overall fitness. The excess eggs will be wasted, as more animals die off from resource limits. But no retreat will be possible: a less fecund individual will be relatively less fit (Gould and Lewontin 1978). Such fitness 
sinks exist because there is an important distinction between response-dependent and response-independent fitness effects. Improved vision; stronger bones; improved resistant to parasites and pathogens - all these improve an agent's prospects in a wide variety of environments, in part because these fitness benefits do not depend on specific responses by the agent's social partners. That is not true of, for example, changes in an agent's repertoire of signals, responses, and co-ordination capacities. The capacity to signal trustworthiness in co-operative exchanges is adaptive only if there are co-operators that will read and believe the signal. The fitness consequences of signaling and most other social behaviors are response-dependent, and that sets up the danger of fitness sinks.

It follows that selection on culturally transmitted traits is the most likely cause of our fitness traps. For many (perhaps most) of our social behavior depends for its development on cultural transmission. Moreover, such traps may well be quite common. The widespread and clearly costly practice of female genital mutilation (widespread in a number of North African populations) may well exemplify this problem. A striking fact about this practice is that many who practice it, and who intend to continue practicing it, disapprove of it. For undergoing female genital cutting has become essential to marriageability in the local environment (Mackie 1996; Bureau 2001). So individuals, even when they disapprove of the practice, cannot defect from it as individuals without severe penalty. ${ }^{4}$ The actual origin and establishment of female genital cutting is not known, but it fits the fitness trap model. For female genital cutting could initially establish as a commitment signal: a poor family can marry up if the bride can send an unmistakably honest, because expensive, signal of fidelity. She can buy her way up, thus improving, at a price, her own prospects and those of her family. But once this practice is copied, it becomes a default. Girls can no longer improve their position relative to others by female genital cutting. They can only penalize themselves (perhaps massively) by abstaining from it. So once established, individuals cannot profitably defect from this convention, even when most of them would like to so.

The same pattern seems to fit foot binding. Foot binding, like female genital cutting, imposed clear and obvious costs. Since it involved crushing the feet of small girls, it was appallingly painful for them, and as adults, female mobility was much restricted. It began as an elite practice, apparently serving both as a means of sexual control (though the loss of mobility) and to advertise status. So it seems to have spread via an arms race: bound feet were a necessary condition of marrying up, and so, increasingly, all girls had their feet crushed, initially to improve their position in the marriage market, and then to have a position in the marriage market (Mackie 1996). As the practice went to fixation, everyone was worse off than they were, but no one could afford to defect individually (Edgerton 1992: 134-135). ${ }^{5}$ Initiation rituals may well have a similar dynamic. On this model, they begin as expensive signals of courage, of the capacity to endure pain, and of endurance. They thus buy prestige and status. But they then become mandatory for all, and hence leave their residue of costs without any benefits. ${ }^{6}$ Moreover, as Robert Frank has pointed out, once this signaling system establishes, even if an agent cannot produce a fully convincing signal of endurance, courage, and pain tolerance, sending no signal at all is worse than sending a weak signal. For those monitoring signals will read the null signal as advertising the feeblest of cowardice (Frank 1988).

Fitness traps, like conflicts between levels of selection, depend on the fact that humans live in complex social worlds with only partially aligned reproductive interests. Unlike interlevel conflict, the fitness trap model does not depend on the idea that the group itself is an adapted unit. Gusii-like sexual politics might be a fitness trap rather than group-level maladaptation caused by individuals pursuing their own interests. In general, though, economic advantage does translate into fitness advantage, and individuals profit from social practices that concentrate resources in their hands, even when those social arrangements are collectively maladaptive. So adaptation at one level is constrained by selection at another. This constraint on adaptation is not unique to cultural evolution, but it may be more pervasive in the cultural rather than the biological world, for in considering human culture, there is no focal level of adaptation parallel to the multi-celled organism. For many purposes, evolutionary biologists can treat the multi-celled organism as the adapted unit, and ignore the complications of multilevel selection. That is not true of human agents and the social groups they form. For human culture has features which tend to entrench differences between groups; which tend to make groups more homogenous in important respects (food preferences; foraging and resource use practices; marriage customs), and which tend to make shifting between groups uncommon and difficult. These features make cultural group selection powerful. Through the period in which human populations were divided into many culturally different groups, selection on groups was an important constraint on individual adaptation. But since groups are never perfectly homogeneous, and since migration is rarely utterly impossible, selection on individuals was also of continuing importance, constraining group-level adaptation (Boyd and Richerson 1992; Richerson and Boyd 1999; Boehm 2000; Richerson and Boyd 2001).

\section{Memetic Outlaws}

The genes that compose an organism's genome do not always have the same evolutionary fates: the selection of sex ratio distorters and other selfish genetic elements has consequences of organism phenotypes. Such examples show that competition between gene lineages sometimes constraints individual 
organism adaptation (Burt and Trivers 2005). Even though we often ignore the complications of multilevel selection, there is a near-consensus that selection does not act only on organisms. There is a major controversy on whether the evolution of adaptation mediated by cultural inheritance is constrained the same way; a debate that turns on the appropriate assessment of the meme model of cultural inheritance. In meme-based models, the meme itself has fitness properties, and these are defined by its potential to replicate, not its bearers' propensity to breed. These two potentials need not correlate well. One contrast between genetic and cultural inheritance is that while only our children inherit our genes, there is no such restriction on our distinctive ideas.

Notoriously, Dawkins (2003) has exploited this fact to explain cognitive maladaptation. Religion is the result of viruslike non-vertical transmission. On this view, the power of cultural evolution to build adaptations that increase our fitness is constrained by the evolution of memetic outlaws that spread because cultural transmission is not vertical. According to cognitive anthropologists, this is a vivid but empty metaphor. To explain religion we need to know why humans find religious ideas salient, credible, memorable. Religion would not be part of human social life if people found religious ideas absurd, uninteresting, or incomprehensible (see, e.g., for example, Sperber 1996; Boyer 1999, 2000, 2002; Atran 2001).

On this view, we understand human irrationality by understanding the intrinsic psychology of humans; we understand religion when we find out why humans find credible explanations of their environment in terms of occult forces. In contrast, Dawkins' explanation is external: his explanation emphasizes human networks of information flow. Network shape matters. In small-scale social environments in which people transmit many of their ideas to their kin in the next generation, and in which there is a reciprocal dependence on one's neighbors, ideas and genes will be filtered in somewhat similar ways. In large-scale and more open networks, the transmission potential of ideas will be very different from that of genes. With different network shapes, the costs and benefits of cultural learning change. So it is possible to construe the Boyer-Sperber explanation as complementing Dawkins' explanation rather than contradicting it. All selection depends on variation, and the cognoviral theory of religion has no theory of variation. Boyer (for example) does have a theory of variation: religious ideas are of the familiar transformed. Their familiarity makes them comprehensible; their transformation makes them salient. A full explanation of religion combines an account of the source of variation with an explanation of why variants with deleterious effects on their hosts are not filtered by selection. In that explanation horizontal idea flow plays a crucial role (for a similar line of argument, see Dennett 2006, appendix c; thanks to Joe Bulbulia for pointing this out to me).
On this way of thinking about Dawkins and the cognitive anthropologists, they differ on the relative importance of selection and the supply of variation. As we noted in Section 1 , biases in the supply of variation make some evolutionary trajectories more likely than others. Atran, Boyer, and their allies have a "developmental drive" theory of the genealogy of religion. But even if they are right, that does not make Dawkins' selective considerations irrelevant. In particular, the fact that large-scale, largely horizontal networks of cultural information flow have been established relatively recently is important. Superstitious beliefs are expensive. The Inuit's fears of the nonexistent impose real costs on them, though these are minor in comparison to those imposed by many religions. So if the cognitive biases that produce religious and superstitious ideation were virtually universal, we would expect effective selection against the cognitive biases that produce them. In view of their expense, we need some explanation of the persistence of the cognitive biases that produce them. ${ }^{7}$ One recently popular suggestion is that religious cognition is adaptive despite the false picture of the world it encapsulates; it enhances cooperation with all its benefits (Wilson 2000; Bulbulia 2004). Dawkins has an alternative selective model: changes in human cultural networks make outlaw memes harder to purge. Religion on this combined model is explained by (1) biases in the supply of variation; (2) the current structure of large-scale open networks; and (3) the fact that those large open networks are relatively new.

\section{Hill Climbing, Cumulative Evolution, and Cultural Transmission}

There is a standard criticism of evolutionary models of culturally mediated adaptation. Cultural transmission is low-fidelity (the argument goes), and the cumulative, selection-guided evolution of complex adaptation depends on high-fidelity transmission. For small improvements have to be preserved and amplified to high frequency in descendant populations to serve as a basis for further small improvements. ${ }^{8}$ One response to this line of argument is to argue that (in the right environments) cultural transmission is high fidelity (Sterelny 2003; Jablonka and Lamb 2005). The other is to argue that multiplesource transmission makes possible the evolution of adaptive response to environmental challenges. For by adding redundancy, it compensates for noisy transmission from the informed to the ignorant. Thus Boyd and Richerson argue that multiple-source transmission helps explain the adaptive power of cultural evolution. It compensates for the low fidelity of one-on-one cultural learning. Conformist and success biases explain the preservation and amplification of information in the face of noise. A conformist bias, for example, adds redundancy to the system, increasing the effective rate of exposure to crucial information. Success biases accelerate the rate 
at which an innovation spreads through a population, more rapidly making that innovation available as a platform for further improvement, and making it less likely to drift to extinction. For adaptive novelties can be lost very easily when they are still rare (Henrich and Boyd 1998, 2002; Richerson and Boyd 2001, 2005).

However, there are crucial differences between vertical and multiple-source transmission. To implement a success bias, agents have to be able to recognize success. In models in which a success bias plays an important role, the recognition of success rather than just success is crucial. Yet in many circumstances, recognizing success is cognitively difficult. When the returns for different practices do not vary dramatically, agents must make an appropriate inference from statistical data, and we are not good at this. If multiple-source transmission is central to the transmission of an adaptive response to the environment, and the signal of success is hard to recognize amongst the noise, we should not expect adaptive accommodation.

Consider, for example, Marvin Harris's Panglossian defense of food taboos. In Good To Eat, he argues that food taboos are in general adaptive responses to local economic and ecological considerations. Some of these local adaptations do not seem to be epistemically challenging. The Islamic-Jewish prohibition on pork (he argues) is a response to the fact that pigs are economically ill-suited to Middle Eastern domestication. For Middle Eastern farmers needed animals that could live on grass. ${ }^{9}$ Success and failure here would be easy to detect, both with respect to one's own practice and that of others, as pigs simply do not gain weight on diets on which ruminants thrive. But other adaptations, on Harris's own analysis, are very challenging. These involve complex tradeoffs between long-term and short-term benefit, and between different nutritional benefits. So (for example) he suggests apparently wasteful foraging practices (taking only a few cuts of meat from a carcass) are in fact adaptive responses to the need to eat fat at the same time as protein (else the protein will not be absorbed as protein) (Harris 1985: 42-43).

In a noisy world (in which health and vitality are influenced by many causal factors) the modest differences in health caused by modest differences in dietary practices would be difficult to detect. It is not difficult to see how the recognition of success and failure can discourage adopting disastrous practices, and facilitate the adoption of manifestly and markedly superior ones (for example, shifting from stone to metal axe heads). But biological evolution involves hill climbing: the selection of a slightly superior version of a trait over a slightly inferior version. One of the early triumphs of population genetics was the demonstration that small but consistent fitness differences are indeed visible to selection. Over time, a modestly fitter version of a trait will replace an inferior alternative. Hill climbing is possible in gene-based evolution. It is possible in dual inheritance models, if cultural transmission is high fidelity. To the extent that cultural transmission involves conformist biases, hill climbing is blocked. For if an ignorant but conformist agent notices the difference between the innovative and the majority practice, conformism mandates choosing the majority practice. (If the difference is not noticed, presumably we would expect some kind of blending.) If cultural transmission involves a success bias, hill climbing is possible only if a naive agent can recognize small differences in the success of a technique (as well as small differences in the technique itself). It is not obvious that this constraint on hill climbing is consistently satisfied.

This epistemic constraint is exacerbated by environmental instability. Hill climbing requires stable hills: it is less effective in unstable environments, for the hill can disappear before the population reaches the top. Moreover it is especially difficult to recognize success if the environment is unstable. To the extent that cumulative adaptation depends on the recognition of success, not just success, environmental instability makes adaptive response doubly difficult.

To see this, consider the contrast between our capacities to kill and to cure. Human weapons technologies have been more uniformly impressive than our health technologies. Folk medicine is not uniformly hopeless: small societies have quite often exploited the curative powers of naturally occurring drugs: for example curare, coca, quinine, ephedrine, and opium. But many traditional practices are not just useless but dangerous. As Edgerton notes, some cultures were ignorant of even very basic surgical procedures. Despite the incessant warfare that characterized their lives, the Mae Enga were hopelessly inefficient at dealing with arrow wounds. Thus

Acting on the Mae Enga belief that the wounded man's blood was contaminated, a specialist used a bamboo knife to make an incision under the victim's armpit and then broke a rib with a wedge so that he could insert two fingers into the thorax, collapsing a lung in the process. He next poured water into the cavity and shook the patient vigorously to mix the blood and water. Finally, he rolled the patient over to drain out the mixture. (p. 106)

Amazingly, some survived this help. This is perhaps Edgerton's most spectacular example, but he has a chapter-length review of health catastrophes in folk society, many of which (he suggests) are the result of medical incompetence. For example, in very many cultures, even when they are available, protein and other high quality foods are denied to pregnant women and young children, thus exacerbating diseases of malnutrition.

One reason, I conjecture, is that the problem of health and ill health is epistemically intractable. The causes of sickness are multiple, and even successfully interventions have probabilistic effects. Placebo effects make it difficult to separate the physiological effect of a treatment from the psychological benefits of being the focus of help. It is often difficult to 
tell whether a putative "cure" has worked. Edgerton, I think, overlooks the importance of this epistemic constraint. He is, for example, puzzled by the widespread practice of delaying breast feeding until the breasts provide true milk. He points out that colostrum is very important in arming the newborn baby's immune system, and hence this practice is quite seriously maladaptive; and he quotes with approval Jerome Barkow's remark that the dangers of denying colostrum to babies are obvious (p. 117). But Edgerton's own discussion shows that this is far from obvious. As he himself remarks, many factors are causally relevant to infant death, and so there was no clear evidence showing that the longer breast feeding is delayed, the greater the health risk to children. Crucial evidence comes from animal experiments. But no effect that can be shown only through controlled experiment is obvious. Likewise, Edgerton is puzzled by the widespread use of fava beans. For those that lack the right enzyme can become seriously ill (even fatally ill) from eating them. But the proportion of people likely to become seriously ill is fairly small, and even for those at risk, the effects are masked epistemically by the fact that fava beans are typically eaten with other food and sometimes cooked in ways that reduces their toxicity to the vulnerable. So the benefits of fava beans are obvious: they are tasty and easy to grow. Their costs are not obvious.

Moreover health environments are highly labile. Cognitive capital can accumulate by variation and the retention of successful experiments only if environments change relatively slowly (Boyd and Richerson 1996). Cultural evolution may be too slow to track health environments. Microbes themselves evolve very rapidly. Antibiotic resistance can evolve in months or even weeks. Furthermore, the changes people make to their own worlds change the pathogens that challenge them. An increase in population size can ensure that a pathogen population will always have access to immunologically naive hosts and hence will not die out. New farming techniques can create opportunities for disease vectors to breed. Husbandry can create opportunities for pathogens to host switch. Odling-Smee and his collaborators point out that many of the crowd diseases characteristic of dense human populations (measles, tuberculosis, small pox, flu, and the like) entered human populations from domesticated animals (Odling-Smee et al. 2003: 347). The yam-cultivating Kwa speakers of Africa are one of their standard examples of gene-culture coevolution; their farming practices created new breeding grounds for malaria carrying mosquitos, which in turn selected for the malaria-resisting sickle-cell allele (pp. 261-262).

The evolutionary volatility of pathogens and the role of human activity in changing pathogen selective environments are important themes of Paul Ewald's Evolution of Infectious Disease. In this work, Ewald (1994: 68) introduces the concept of a cultural vector: a human activity or environmental modification that allows transmission from an immobilized host to new targets of infection. Ewald argues that early urbanization and water engineering selected for virulent strains of cholera and dysentery. Virulent strains-potentially lethal varieties - immobilize their victims, causing uncontrollable diarrhea. In nomadic, low-density populations, these potentially lethal variants are evolutionary dead ends. For these immobilized hosts and their contaminated wastes will be in contact with few potential targets. But with increasing population density and especially pre-modern water engineering, the population of potential new targets expands, and their vulnerability increases through the contamination of drinking water by diarrheal waste. In these new villages, towns, and cities, water "flows like mosquitos," connecting the already ill with the as yet uninfected. These new, human-created environments select for virulence (since immobilizing the host no longer blocks further transmission), and microbes respond to the new selective regime with extraordinary speed. Purifying water removes the cultural vector and selects for the older, less virulent strains: an effect for which Ewald assembles impressive evidence.

In short, the problem of health and disease confronted human cultures with highly labile environments, for humans themselves change their own physical, biological, social, and demographic environments, sometimes very rapidly indeed. In doing so, they both changed the array of pathogens to which they were exposed and changed the selective environments of familiar pathogens. Those pathogens in turn were capable of responding with great speed in those new selective regimes. None of this would be obvious. The environmental changes that confronted populations with new risks were part of a transformation in lifeways. As nomads became farmers and villagers, they ate new food, used new technology, lived in larger and less mobile groups, and used new technologies. It would be difficult to identify the crucial, pathogen-exposing element in this complex of changes. Moreover, pathogens themselves are invisible and often do not have unique effects. The same symptoms can have different causes. Humans often recovered from their infections. Sometimes they would recover despite the interventions of other humans, interventions that in fact lowered the probability of survival. Sometimes they would die despite interventions which, in fact, increased they chance of survival. False confirmations and false disconfirmations make interventions difficult to assess. Highly labile domains and those for which the success and failure of experiments are hard to judge will not support the cumulative growth of cognitive capital. Both of these problems infect human response to the challenge of pathogens. Jointly they help explain why folk medicine has not hill-climbed to success.

Finally, folk medicine is a special (though extreme) case of a more general phenomenon. Humans are not the only nicheconstructing organisms, but we are especially pervasive and persistent in our niche construction, changing our environments profoundly and repeatedly. The variability of human 
environments selects for mechanisms of adaptive plasticity. In our case, adaptive plasticity often involves the capacity to vary behavior in response to variation in the environment. This, in turn, means that the development of phenotypically plastic aspects of human phenotypes is sensitive to the cultural context of the developing child. To put it as a slogan: the genes have off-loaded the problem of environmental instability to memes. And the chalice is poisoned. Those aspects of our phenotype especially sensitive to culturally transmitted information will be those that mediate our response to unstable and informationally translucent features of our environment.

\section{Holism and the Supply of Variation}

Lewontin (1978) pointed out the connection between evolutionary plasticity and phenotypic modularity. A trait can readily respond to selection only if it can vary independently of the rest of the phenotype. If varying one trait involves changing many, it is almost certain that the fitness costs of these other changes will overwhelm the fitness advantage of change in the focal trait. ${ }^{10}$ So to what extent can we see cultures as aggregates of more or less autonomous information packages varying independently of one another; to what extent are they linked, cohesive ensembles? As we shall see, this question arises both for populations and for individual agents. I begin with populations, and with a prima facie distinction between norms and technologies. The idea is that differences in the supply of variation lead to technologies being filtered by selection more effectively than norms.

Consider, for example, the social norms that determine whether a son moves to his wife's village. Notice, first, that individual learning will not optimize such norms. For this is not a social arrangement an individual can trial in his own life: trying first the one, and then others. In most social environments, trial and error cannot be supplemented by observing the success and failure of others. For central features of family organization tend to be subject to norms which largely eliminate variability. Norms tend to be homogenized within groups. This makes both individual learning and selection less effective. Selection has little variation with which to work, and individual learning is deprived of comparative data. Even in an environment with varying customs about family organization, those are likely to be highly correlated with other differences: in religion, ethnicity, and economic organization. Norms are not very modular. This makes both selection less powerful. As groups tend to be homogenous, selection within the group will not tend to optimize norms. Since marriage practices are typically linked with other traits, cultural group selection is less powerful in filtering to less adaptive marriage practices. For marriage rules will usually be part of complexes of social behavior, and hence will not be individually exposed to cul- tural group selection. It is only the complexes as a whole that are filtered.

As Stephen Shennan notes, the fact that marriage norms do not vary independently of other regularities of social behavior within cultures is no accident. For as we encounter one another, we face many coordination problems. In solving such problems, it helps to interact with other agents who have similar expectations about social interaction, family organization, child rearing, norms of politeness, and the like. It is much easier to interact with other agents who behave as you expect, because they behave as you would behave, were you in their circumstances. Sets of such practices will tend to become associated (Shennan 2002). They will become a single package. In contrast, technological and craft skills are more modular. As many folk in shared houses have found, you cannot live easily with someone with very different ideas about polite interaction; who prepares the food; what is a delicacy and what is disgusting; whether children should be treated gently or roughly. But there is no problem living with someone who prefers to use a different style of fishhook. For the same reason, technologies often diffuse beyond the boundaries of the groups in which they are invented.

I think the distinction between the modularity of technical skills and the linkage of norms of social life is essentially correct. It is important to remember, though, that the distinction is one of degree, and that there are many complicating factors. The example of the Greenland Norse exemplifies these complications, showing we should not overstate the extent to which technology is modular. The Norse settlement of Greenland survived for about 400 years, before going extinct in the mid C15. They went extinct while sharing the same environment with Greenland Inuit groups that survived using their arctic technology. The Norse did not borrow this technology (they persisted with farming). So they did not borrow crucial kayak, umiaq, and harpoon technology. They were severely food stressed, and without this technology they harvested seals less effectively and whales not at all. Even more surprisingly, and like the Tasmanian aborigines (who were also food stressed though winter), they did not exploit fish either. They also failed to borrow Inuit use of oil for cooking and heat, despite being very short of fuel too. If technology is modular, then this failure of transfer is puzzling.

Perhaps technology is not as quasi-independent as I have suggested. Technologies can often be central to cultural identity, so borrowing would transform cultural identity as a whole. In other words, technology itself might be normatively marked. The Norse thought of themselves as farmers, not as primitive hunters. But while Diamond makes this suggestion in discussing the Norse in Collapse, somewhat later the Danes, from the same cultural roots as Greenland Norse, borrowed Inuit technology freely without becoming Inuit. A more plausible constraint is knowledge. Inuit technology depended on 
a rich and specialized skill base. It is one thing to shift from stone to steel axe heads. For a steel axe is an incremental improvement of a tool of the same type. It has a commensurable purpose and skill base. Even substituting firearms for bow and arrow technology will have a partially commensurable skill base. The local ecological knowledge and field craft essential to bow and arrow hunting will be deployed in hunting with firearms, too. In contrast, Inuit technology was largely incommensurable with Norse technology: the skills needed for its use would have to be built from scratch. It is not easy to hunt from kayaks, and in icy seas the cost of error was very high. Moreover, the Norse were not able to afford experiments or invest time in developing new skills and technologies. Their cultural world lacked redundancy. Diamond makes much of the marginal nature of Greenland and of the stressed time and food budgets of the Greenland Norse. It is quite likely that they could not afford the costs of re-skilling imposed by technological transfer. A fitness valley separated them on their sinking local optima from the globally optimal set of Inuit adaptations. I suspect we can explain the Norse as a genuine exception; and there is a real difference in the supply of variation at the population level between norms and artifacts.

A similar distinction may be important in individual ontogeny. Sections 2-4 were mostly about the relationship between phenotype and fitness, and how selective environments constrain evolutionary possibility. But in thinking about genetic inheritance, the relationship between genotype and phenotype is crucial, for that relationship determines whether genetic variation corresponds to selectable phenotypic variation. So even if at the level of culture there is variation in informational packages - say, variation in fishing lore or parenting ideology — those variations in lore about a specific activity may not be manifest in consistent differences in practice. They will not be difference makers for such practices. Yet it is practice, presumably, that determines the success or failure of agents as they interact with their world. ${ }^{11}$ Here too it is plausible that there is a difference between technology and the skills in using it, and norms.

Thus Joseph Henrich (2004) argues that Tasmanian aborigines were poorly adapted to their environment; they lost (or perhaps failed to develop) crucial technological resources: they had limited control over fire; they used marine resources very suboptimally; their hunting technology was depauperate, as was their ability to make clothes from skins. Henrich explained maladaptation through population size: with small effective populations (after the Tasmanians were cut off from the mainland), multiple-source transmission becomes a less effective buffer: it is much less effective at adding redundancy to the system to compensate for parent to offspring misfires. The more important oblique transmission is in maintaining the cognitive capital of a group, the more likely it is that small population loose cognitive capital. He reads the Tasma- nian story as confirming this general picture. Dwight Read (in press) disputes both the claims about Tasmanian society and Henrich's models.

One of the issues between Henrich and Read is whether, in considering cultural transmission, it is important to distinguish between skill (narrowly understood) and other informational resources. Henrich denies that this is an important distinction, but consideration of the replicator-phenotype map suggests that it may well be. Skill is modular: the cognitive resources that power a specific skill (for example, the pattern recognition skills that enable foragers to recognize the animals they see from the most fleeting glimpse) are expressed only in powering foraging skills. ${ }^{12}$ The same is not true of ideology-of the forager's beliefs. Inferential linkage makes the phenotypic expression of belief much less modular and much less predictable. This leads to the idea that (for example) selection will be much more effective in optimizing technology, foraging styles, and the like than it will in optimizing norms and, more generally, the ideological elements of culture. It sifts ideological variation less effectively. Ideology might vary within a group and be transmitted with high fidelity down family lineages without those differences being difference makers: generating consistent differences in specific traits, which would then be visible to selection.

\section{Finale}

There are features of cultural inheritance systems that constrain the generation and retention of variation, and in some ways these constraints bite on cultural transmission more severely than analogous constraints bite on genetic transmission: in cultural transmission systems fidelity, for example, is less secure and less independent of phenotypic effect. But SNAFUS are not caused only, or mainly, by biases in the supply an retention of variation, but as well by the fact that selection on culturally transmitted variation is powerful at a number of levels, and by the systematic offloading of tough problems onto culturally mediated mechanisms of adaptation. The genes have kept the easy jobs for themselves.

\section{Notes}

1. "SNAFU"- “Situation Normal, All Fucked-Up."

2. The contrast is with symbiotic micro-organisms. This inheritance system is of great evolutionary importance, opening up whole new adaptive zones for the hosts of those organisms. But it is evolutionarily conservative: the micro-organisms which make it possible for termites to digest wood are never going to transform their hosts' phenotypes in any other way.

3. Moreover, collectively suboptimal actions can result from willingness to punish, to retaliate, not just from tragedies-of-the-commons. There is quite good evidence that people are "strong reciprocators": they enter situations of potential cooperation prepared to honestly cooperate if they expect others will do so to, but also disposed to punish failures of cooperation, even at net personal cost (Fehr and Fischbacher 2003, 2004). The breakdown of 
cooperation into feuding can be more destructive than the failure to establish cooperation.

4. Somewhat surprisingly, there is some debate about whether this practice is costly. But even setting aside psychological issues, any genital surgery performed in non-sterile conditions must risk serious infection, and there is plenty of evidence of such infections and their biological costs. Both the debate and the costs are discussed in Gerry Mackie's excellent (2003); for the alternative view, see Obermeyer (2003). Since individuals cannot defect without costs, yet many disapprove, female genital cutting sets up a coordination problem; if the group as a whole can persuade itself to abandon female genital cutting, everyone will be better off. Mackie discusses quite encouraging signs that this coordination problem can be solved (perhaps with outside help and stimulation). The possibility of deliberate, consensus decisions at the group level to change a practice is, of course, one very important difference between gene-based change and cultural change.

5. The speed with which it disappeared in the face of external shocks and internal attempts to co-ordinate its abandonment suggests that those imprisoned by the practice were aware of the trap they were in. It disappeared from urban areas in about a decade, early in the 20th century.

6. Edgerton notes that there are many ethnographic examples of the rapid, uncontested abandonment of some of these more extreme initiation rituals in colonial encounters (pp. 140-141); a hint, perhaps, that those agents were aware of being caught in a fitness sink.

7. An alternative developmental explanation would be to argue that the propensity to generate and accept religious ideas is not a trait that can vary independently of other aspects of cognition (it might, for example, be linked to empathy, imagination, or mind-reading skills). Since attraction to religious ideas clearly varies in strength in human populations, developmental hypotheses of this kind are testable. We would test whether religiosity varied independently of other aspects of cognition.

8. For the importance of high fidelity, see Ridley (2000), Sterelny (2001, 2004), Dawkins (2003); for the argument that cultural transmission is low fidelity, see Atran (2001), and Gil-White (2005).

9. Why one would need to prohibit such an untempting local practice is less clear.

10. The background idea is that most possible phenotypes are not viable. So if one begins with a viable phenotype and makes many changes, the result is probably one of the many unsurvivable phenotypes.

11. A further, and perhaps important, contrast between fishing and parenting is that what people say about their parenting is part of their parenting; that is not true of fishing.

12. To a first approximation: perhaps they are expressed in art and ritual, in teaching children these skills, and the like. So more accurately: in foraging and ancillary skills.

\section{Acknowledgments}

Thanks to Joe Bulbulia, Celia Heyes, and John Odling-Smee for their comments on an earlier version of this article; thanks also to the participants in the ANU Inheritance workshop for their feedback on a still earlier version.

\section{References}

Arthur W (2004) Biased Embryos and Evolution. Cambridge: Cambridge University Press.

Atran S (2001) The trouble with memes: Inference versus imitation in cultural creation. Human Nature 12: 351-381.

Boehm C (1999) Hierarchy in the Forest. Cambridge, MA: Harvard University Press.
Boehm C (2000) Conflict and the evolution of social control. Journal of Consciousness Studies 7: 79-101.

Boyd R, Richerson PJ (1992) Punishment allows the evolution of cooperation (or anything else) in sizable groups. Ethology and Sociobiology 13: 171195.

Boyd R, Richerson PJ (1996) Why culture is common but cultural evolution is rare. Proceedings of the British Academy 88: 77-93.

Boyer P (1999) Cognitive tracks of cultural inheritance: How evolved intuitive ontology governs cultural transmission. American Anthropologist 100: $876-889$.

Boyer P (2000) Evolution of the modern mind and the origins of culture: Religious concepts as the limiting case. In: Evolution and the Human Mind: Modularity, Language and Meta-cognition (Carruthers P, Chamberlain A, eds), 93-112. Cambridge: Cambridge University Press.

Boyer P (2002) Religion Explained: The Human Instincts that Fashion Gods, Spirits and Ancestors. New York: Vintage.

Bulbulia J (2004) Religious costs as adaptations that signal altruistic intention. Evolution and Cognition 10: 19-38.

Bureau PR (2001) Abandoning Female Genital Cutting: Prevalence, Attitude, and Efforts to End the Practice. Nairobi: Population Reference Bureau.

Burt A, Trivers R (2005) Genes in Conflict: The Biology of Selfish Genetic Elements. Cambridge, MA: Harvard University Press.

Dawkins R (1982) The Extended Phenotype. Oxford: Oxford University Press.

Dawkins R (2003) A Devil's Chaplain: Reflections on Hope, Lies, Science, and Love. Boston: Houghton Mifflin.

Dawkins R (2004) Extended phenotype-but not too extended. A reply to Laland, Turner and Jablonka. Biology and Philosophy 19: 377396.

Dennett DC (2006) Breaking The Spell: Religion As A Natural Phenomenon. New York: Viking.

Diamond J (1992) The Third Chimpanzee: The Evolution and Future of the Human Animal. New York: Harper Collins.

Diamond J (1998) Guns, Germs, and Steel: The Fates of Human Societies. New York: Norton.

Diamond J (2005) Collapse: How Societies Choose to Fail or Survive. London: Penguin-Allen Lane.

Dupré J, ed (1987) The Latest on The Best: Essays on Optimality and Evolution. Cambridge, MA: MIT Press.

Edgerton RB (1992) Sick Societies: Challenging The Myth of Primitive Harmony. New York: Free Press.

Ewald PW (1994) Evolution of Infectious Disease. Oxford: Oxford University Press.

Fehr E, Fischbacher U (2003) The nature of human altruism. Nature 425: 785-791.

Fehr E, Fischbacher U (2004) Social norms and human cooperation. Trends in Cognitive Science 8: 185-189.

Frank R (1988) Passion Within Reason: The Strategic Role of the Emotions. New York: Norton.

Gil-White F (2005) Common misunderstandings of memes (and genes): The promise and the limits of the genetic analogy to cultural transmission processes. In: Perspectives on Imitation: From Mirror Neurons to Memes (Hurley S, Chater N, eds), Cambridge, MA: MIT Press.

Gould SJ, Lewontin RC (1978) The spandrels of San Marco and the Panglossian paradigm: A critique of the adaptationist programme. Proceedings of the Royal Society London B205: 581-598.

Harris M (1985). Good To Eat: Riddles of Food and Culture. New York: Simon and Schuster.

Henrich J (2004) Demography and cultural evolution: Why adaptive cultural processes produced maladaptive losses in Tasmania. American Antiquity 69: 197-221. 
Henrich J, Boyd R (1998) The evolution of conformist transmission and the emergence of between-group differences. Evolution and Human Behavior 19: 215-242.

Henrich J, Boyd R (2002) On modelling cognition and culture: Why cultural evolution does not require replication of representations. Culture and Cognition 2: 87-112.

Jablonka E, Lamb M (2005) Evolution in Four Dimensions. Cambridge, MA: MIT Press.

LeVine RA (1959) Gusii sex offenses: A study in social control. American Anthropologist (New Series) 61: 965-990.

Lewontin RC (1978) Adaptation. Scientific American 239(3): 156-169.

Mackie G (1996) Ending footbinding and infibulation: A convention account. American Sociological Review 61: 999-1017.

Mackie G (2003) Female genital cutting: A harmless practice? Medical Anthropology Quarterly 17: 135-158.

Mayer P (1952) Gusii initiation ceremonies. Journal of the Royal Anthropological Institute of Great Britain and Ireland 83: 9-36.

Maynard Smith J (2000) The concept of information in biology. Philosophy of Science 67: 177-194.

Obermeyer CM (2003) The health consequences of female circumcision: Science, advocacy, and standards of evidence. Medical Anthropology Quarterly 17: 394-411.

Odling-Smee J, Laland K, Feldman MW (2003) Niche Construction: The Neglected Process in Evolution. Princeton: Princeton University Press.

Orzack S, Sober E, eds (2001) Adaptationism and Optimality. Cambridge: Cambridge University Press.

Read D (in press) Tasmanian knowledge and skill: Maladaptive imitation or adequate technology. American Antiquity.

Richerson PJ, Boyd R (1999) Complex societies: The evolutionary origins of a crude superorganism. Human Nature 10: 253-289.

Richerson PJ, Boyd R (2001) The evolution of subjective commitment to groups: A tribal instincts hypothesis. In: Evolution and the Capacity for Commitment (Nesse R, ed), 186-220. New York: Russell Sage Foundation.
Richerson PJ, Boyd R (2001) Built for speed, not for comfort. History and Philosophy of the Life Sciences 23: 423-463.

Richerson PJ, Boyd R (2005) Not By Genes Alone: How Culture Transformed Human Evolution. Chicago: University of Chicago Press.

Ridley M (2000) Mendel's Demon: Gene Justice and the Complexity of Life. London: Weidenfeld and Nicholson.

Sahlins M (1968) Notes on the original affluent society. In: Man the Hunter (Lee RB, DeVore I, eds), 85-89. New York: Aldine.

Shennan S (2002) Genes, Memes and Human History: Darwinian Archaeology and Cultural Evolution. London: Thames and Hudson.

Sober E, Wilson DS (1998) Unto Others: The Evolution and Psychology of Unselfish Behavior. Cambridge, MA: Harvard University Press.

Sperber D (1996) Explaining Culture: A Naturalistic Approach. Oxford: Blackwell.

Sterelny K (2001) Niche construction, developmental systems and the extended replicator. In: Cycles of Contingency: (Gray RG, Griffiths PE, Oyama S, eds), 333-350. Cambridge, MA: MIT Press.

Sterelny K (2003) Thought in a Hostile World. New York: Blackwell.

Sterelny K (2004) Symbiosis, evolvability and modularity. In: Modularity in Development and Evolution (Schlosser G, Wagner GW, eds), 490-516. Chicago: University of Chicago Press.

Sterelny K (2006) Cognitive load and human decision, or, three ways of rolling the rock uphill. In: The Innate Mind, Vol. 2: Culture and Cognition (Carruthers P, Laurence S, Stich S, eds), 218-233. Cambridge, Cambridge University Press.

Sterelny K (forthcoming) Social intelligence, human intelligence and niche construction. Proceedings of the Royal Society London B.

Tomasello M (1999) The Cultural Origins of Human Cognition. Cambridge, MA: Harvard University Press.

Wilson DS (2002) Darwin's Cathedral: Evolution, Religion, and the Nature of Society. Chicago: University of Chicago Press.

Windshuttle K (2002) The Fabrication of Aboriginal History. Sydney: Macleay Press. 


\section{Queries}

AQ1. Author: Please provide complete affiliation.

AQ2. Author: Please update the reference if possible.

AQ3. Author: Please check the reference "Dawkins 1982a" cited in the body text does not match the publication year cited in the Reference list "Dawkins 1982" and confirm the correct one.

AQ4. Author please check the word "diaster" and confirm.

AQ5. Author please check the word "cognoviral" and confirm.

AQ6. Author: Please check the repetition of "used new technologies" in the sentence.

AQ7. Author: Please check the reference "Dwight Read (in press) "cited in the body text does appear in the Reference list and confirm and update the reference if possible.

AQ8. Author: Please check the name of the author in the reference "Gerry Machie (2003)" and check the sentence for clarity.

AQ9. Author: Please check the changes made in acknowledgment.

AQ10. Author: Please provide the page ranges.

AQ11. Author: Please cross check the reference citation in text "Richerson PJ, Boyd R (2001)" and confirm.

AQ12. Author: Please check the year of two references "Richerson PJ, Boyd $\mathrm{R}$ (2001)" listed in Reference list wrongly and only once it is cited in the body text and confirm whether you want to cite it in the text otherwise delete the one not cited.

AQ13. Author: Please update the reference with year, volume, and page ranges. 